Lentiviral vectors and stem cells

\section{Stable, long-term label opens doors for gene therapy \\ C Lundberg}

Gene Therapy (2005) 12, 195. doi:10.1038/sj.gt.3302430

Published online 2 December 2004

A new study shows that lentiviral vectors can be used to target and transduce long-term repopulating adult neural stem cells. This finding opens up the possibility of novel therapeutic strategies for previously untreatable diseases of the central nervous system (CNS).

It was once generally thought that the brain could not be mended. If broken it could never become the same, just as a glass window can never be put together again. Santiago Ramón y Cajal first articulated this belief early in the 20th century: 'once the development was ended, the founts of growth and regeneration... dried up irrevocably'. ${ }^{1}$ However, at present it has been proven beyond any doubt that new cells continue to be generated in the adult brain: neurogenesis is clearly an ongoing process. $^{2}$ As early as the 1960s, there were studies that indicated that new neurons were born in postnatal life, ${ }^{3,4}$ but it is the recent rediscovery of this phenomenon that has initiated the recent spate of studies that focus on this area. ${ }^{5,6}$ The potential therapeutic use of adult neurogenesis offers hope to many patient categories with neurological diseases lacking effective cure at present. Now, in a paper in the Proceedings of the National Academy of Science USA, Consiglio et $\mathrm{al}^{7}$ show that they can transfer genes to the stem cells in one of the neurogenic zones of the brain, namely the subventricular zone (SVZ).

Immature cells in the SVZ have been shown to differentiate into the neuronal cell types lost due to lesions such as stroke, ${ }^{8,9}$ but at very low numbers. Neurogenesis in response to such damage would need to be increased in order to provide symptom relief in patients. Interestingly, an array of growth factors have been shown to increase the proliferative response and/or survival of the new born cells, ${ }^{10}$ which clearly opens the door for gene therapy initiatives.
Using oncoretroviral-based vectors, a number of groups have labeled precursors in the SVZ, but the very few of the slowly dividing neural stem cells have been targeted. ${ }^{11-13}$ Consiglio et $a l^{7}$ now show that lentiviral vectors, which transduce both dividing and resting cells, can be used to label immature cells in the SVZ that generate neuronal progeny for as long as 6 months. To further demonstrate that the transduced cells indeed represent a stem cell population, the authors applied an in vitro assay and proved that the GFPpositive cells had self-renewing capacity and after clonal expansion could generate differentiated cell types of all three lineages in the brain - neurons, astrocytes and oligodendroglia.

The implications of these findings are of different flavors. Firstly, these results imply that gene therapy strategies might be developed that allow neurons lost through neurological disease or CNS damage to be replaced: a very exciting prospect. Specifically lentiviral vectors could be used to encourage the stem cells so that they participate more effectively on the healing process of the brain and thus reduce symptoms of disease. The paper by Consiglio et $\mathrm{al}^{7}$ provides us with the first tool to do so effectively in the endogenous neural stem cell population. However, are stem cells the ideal cell to target? The effects of genes transferred to stem cells will be inherited to a large cohort of progeny for a long period of time, possibly for life, and so the influence of this expanding population of transgenic cells might be hard to predict. Further studies are needed to elucidate this and will no doubt gain insight in the endogenous neural stem cell's role in normal brain as well.

Secondly, there are implications from a more technical point of view. The use of lentiviral vectors might complement the use of thymidine analogs to label and study the pro- geny of neural stem cells in the brain especially after damage. The vectors will label all progeny equally and not be diluted in a pool of fast dividing cells, thus providing a more accurate representation of the full proliferative response and its long-term consequences in the brain. Furthermore, lentiviral vectors could be used to create chimeras with specific genetic modifications in the neural stem cell pool, which might be very helpful in uncovering the regulation of the neural stem cells and their differentiation in intact and damaged brain. In this context one of the strengths of lentiviral vectors - the ability to transduce nondividing as well as dividing cells - is also one of their limitations. This ability means that it is likely that at least some postmitotic neurons are modified as well. This might not be a problem if the progeny that will be studied migrate far away from the injection site as in the paper by Consiglio et al. However, this possibility should certainly be taken into account if one needs to study neurogenesis at sites closer to the injection site, such as the striatum, which lays adjacent to the SVZ. Further development of the targeting of the vector itself might provide solutions to this limitation.

C Lundberg is Associate Professor at the Wallenberg Neuroscience Center, Department of Physiological Sciences, Lund University, BMC A11, 22184 Lund, Sweden.

E-mail: Cecilia.Lundberg@mphy.lu.se Published online 2 December 2004

1 Ramón y Cajal S. Degeneration and Regeneration of the Nervous System. Oxford University Press: Oxford, 1991.

2 Gage F. Science 2000; 287: 1433-1438.

3 Altman J. J Comp Neurol 1969; 137: 433-457.

4 Altman J, Das GD. J Comp Neurol 1965; 124: 319-335.

5 Gould E, Gross CG. J Neurosci 2002; 22: 619-623.

6 Kaplan MS. Trends Neurosci 2001; 24: 617-620.

7 Consiglio A et al. Proc Natl Acad Sci USA 2004; 101: 14835-14840.

8 Arvidsson A et al. Nat Med 2002; 8: 963-970.

9 Parent JM et al. Ann Neurol 2002; 52: 802-813.

10 Kokaia Z, Lindvall O. Curr Opin Neurobiol 2003; 13: 127-132.

11 Falk A et al. Exp Cell Res 2002; 279: 34-39.

12 Goldman JE. J Neurooncol 1995; 24: 61-64.

13 Rogelius N, Ericson C, Lundberg C. J Neurosci Methods (in press). 